\title{
AN EXPERIMENTAL STUDY ON THE ADDITIONAL SETTLEMENT OF FOOTINGS RESTING ON GRANULAR SOILS BY WATER TABLE RISE
}

\author{
Blain A. Morgan ${ }^{\text {i) }}$, Sanjay K. Shukla ${ }^{\text {ii)* }}$ and Nagaratnam Sivakugan ${ }^{\text {ii) }}$
}

\begin{abstract}
When the water table rises in a granular soil mass, a large additional settlement of footing resting on such a soil mass is commonly expected. Laboratory model tests show that when the water table rises to the footing level, there can be an additional 400 to $500 \%$ of the settlements compared to when the soil is dry. To understand the mechanics of the additional settlements of footings resting on the granular soil masses caused by water table rise, an investigation into the change in the Young's modulus of soil was therefore made using oedometer tests. A relation between the saturated and the dry Young's moduli of the granular soils is presented for use in the elastic analysis of footing settlements. The findings of the investigation were then used to predict the additional settlements of a model footing when subjected to a water table rise, using elastic analysis. The theoretical predictions of the additional settlements are lower than the actual additional settlements observed in the settlement tests conducted in the laboratory using model tests. The model tests show that the additional settlements are larger in loose sands than in dense sands.
\end{abstract}

Key words: footing, granular soil, settlement, water table rise, Young's modulus (IGC:E2/E14)

\section{INTRODUCTION}

When the water table rises under a footing resting on the granular soil mass, the footing undergoes some settlement in addition to the elastic settlement under normal conditions where the soil remains in dry condition. In the previous studies, these additional settlements due to rise of water table up to the footing level have been observed to be as high as 12 times the dry settlements (Murtaza et al., 1995). There are a number of causes for the additional settlements. Some soils have soluble salts, known as calcareous materials, retained in the soil structure. When dry, these salts provide a strong bond between the soil particles due to their ionic nature; however upon saturation, the salts get dissolved and the bonds are lost. In loose soils, this can lead to significant additional settlements (U.S. Army Corps of Engineers, 1990). The additional settlements can also be partly due to the lubrication mechanism of the soil particles by the water. Another possible cause of additional settlements is the presence of silts and clays in granular soils. When dry, the silts and clays provide a bond between the granular particles; however, upon saturation the bonds are lost. This can also cause some time-dependant settlement in proportion to the fines content until the fines content dominate the consolidation characteristics (U.S. Army Corps of En- gineers, 1990). Capillary tension in moist but not saturated sands can cause an apparent cohesion. This is why the moist sand will hold its shape to some degree. Upon saturation the capillary tension is lost and replaced with pore water pressure. For theoretical analysis, the cause of the additional settlements of shallow foundations however can be observed in the form of a reduction in the stiffness, that is, the Young's modulus of the soil. In this paper, an attempt is made to report the experimental investigation on how the Young's modulus of granular soils changes with saturation due to a water table rise, the settlement test observations made on a model footing resting on the granular soils, and the use of the findings for a comparison with theoretical settlement predictions.

\section{EXPERIMENTAL PROGRAM}

Two granular soils having coarse sand-size and fine gravel-size particles (Fig. 1) were selected with grain sizes large enough to minimise the capillary rise through the soil. The aim of minimising the capillary rise was to try to eliminate the effects of partial saturation and changes in the stress state of the soil which occur from the capillary tension. The visual classifications, grain size distributions, determination of the minimum and maximum dry densities and direct shear tests were conducted as per the

Arup Partners, Cairns, Queensland, Australia.

ii) Adjunct Associate Professor, and Associate Professor and Head, respectively, Discipline of Civil and Environmental Engineering, School of Engineering and Physical Sciences, James Cook University, Townsville, Queensland, Australia

* Also, Associate Professor and Program Leader, Discipline of Civil Engineering, School of Engineering, Edith Cowan University, Joondalup, Perth, WA (s.shukla@ecu.edu.au) and Associate Professor, Department of Civil Engineering, Institute of Technology, Banaras Hindu University, Varanasi, India.

The manuscript for this paper was received for review on September 1, 2008; approved on December 2, 2009.

Written discussions on this paper should be submitted before November 1, 2010 to the Japanese Geotechnical Society, 4-38-2, Sengoku, Bunkyo-ku, Tokyo 112-0011, Japan. Upon request the closing date may be extended one month. 


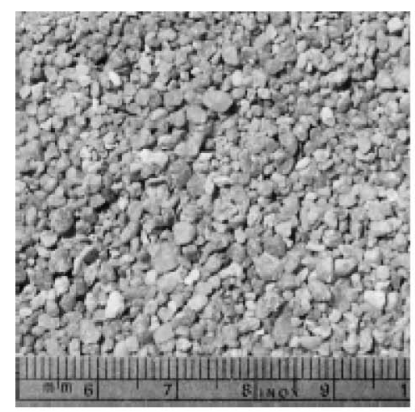

(a) Soil 1

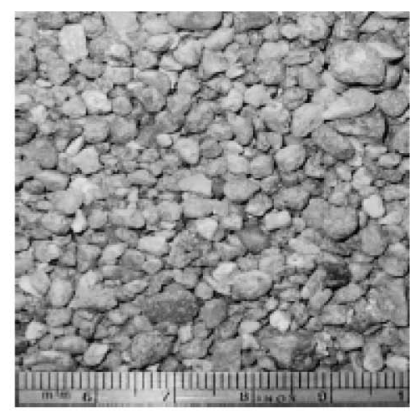

(b) Soil 2
Fig. 1. Photos of the granular soils tested with $\mathrm{mm}$ scale

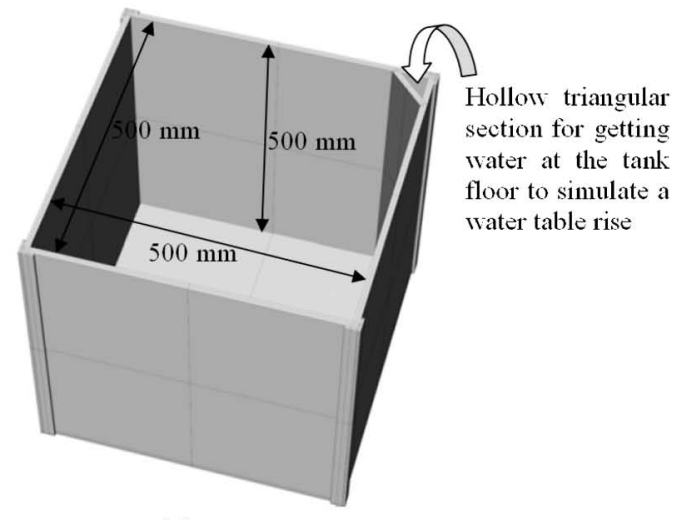

(a)

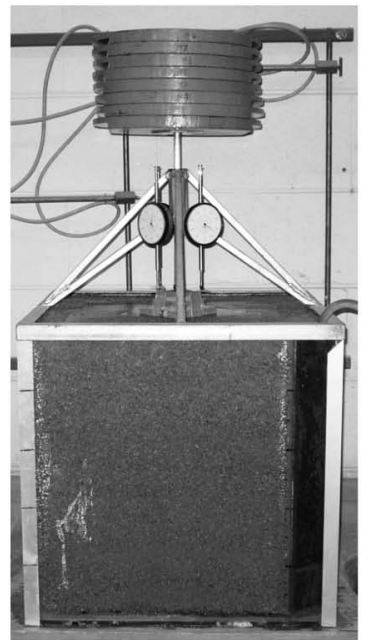

(b)

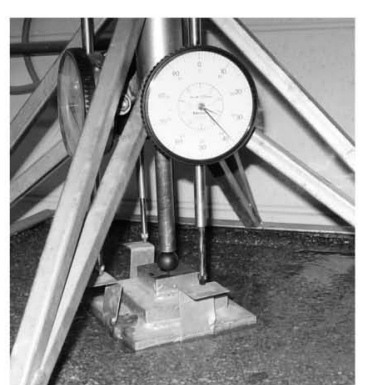

(c)
Fig. 2. (a) An isometric view of cubical glass test tank, (b) a complete settlement test setup and (c) a close view of the footing and dial gauges used in the settlement tests

relevant Australian Standards mentioned in AS1289.0-2000, to build soil profiles and more importantly gather selected properties of the soils. In addition to these basic tests, the oedometer and settlement tests were carried out on the soils at relative densities $\left(D_{\mathrm{r}}\right)$ of $0 \%$ (very loose) and $100 \%$ (very dense). The oedometer tests were conducted to observe how the Young's modulus changed with saturation. To obtain settlement data for comparison with theoretical settlement predictions, the settlement tests were carried out on a model square footing of width $B=100 \mathrm{~mm}$ in a cubical glass tank of side length of $5 B(=500 \mathrm{~mm})$. The test tank had a hollow section in its one corner as shown in Fig. 2(a) for getting the water at the tank floor level to simulate the water table rise. The test involved filling the tank with dry soil to a known relative density (very loose or very dense), loading the model footing on the soil bed and then pouring the water in the hollow section to simulate a water table rise under the footing. The tank was filled with soil in five lifts of $100 \mathrm{~mm}$ thickness. Based on the relative density required, the determined mass of soil for each lift was poured into the tank using a funnel held vertically at a constant determined height and moving around the area of the tank. The top of the soil in each lift was levelled with a wooden float. To obtain the dense condition, each lift was compacted by ramming with metal block. The complete experimental setup is shown in Figs. 2(b) and (c). The water table was raised in increments of $B$ (100 $\mathrm{mm})$ until it was at a depth of $B(100 \mathrm{~mm})$ under the footing. The water rises were then reduced to $B / 5(20 \mathrm{~mm})$ until the water level reached the footing level.

\section{SOIL DESCRIPTION}

The soils tested consisted of two sands. Soil 1 was a coarse sand with a very small percentage (less than $0.1 \%$ ) of silts. It had a maximum particle size of $4.75 \mathrm{~mm}$ with sub-angular yellowish brown particles consisting of quartz and feldspars. Soil 2 was a light brown gravely sand with sub-rounded particles. Both soils were typical of river sands, and their photos are shown in Fig. 1. The minimum and maximum dry unit weights of soil 1 were $14.75 \mathrm{kN} / \mathrm{m}^{3}$ and $16.04 \mathrm{kN} / \mathrm{m}^{3}$ respectively, and of soil 2 were $15.05 \mathrm{kN} / \mathrm{m}^{3}$ and $16.84 \mathrm{kN} / \mathrm{m}^{3}$ respectively. The void ratios were in the ranges of $0.62-0.76$ for soil 1 and 0.54-0.73 for soil 2, between the loosest and densest states. The friction angle for soil 1 ranged from $36^{\circ}$ for very loose to $45^{\circ}$ for very dense and for soil 2 ranged from $39^{\circ}$ for very loose to $48^{\circ}$ for very dense. Permeability of soil 1 was $5 \times 10^{-3} \mathrm{~m} / \mathrm{s}$ at $50 \%$ relative density. Permeability of soil 2 was $8 \times 10^{-3} \mathrm{~m} / \mathrm{s}$ at $50 \%$ relative density. The grains were relatively uniform for both soils, with coefficient of uniformity of 2.6 for soil 1 and 2.8 for soil 2.

\section{INTERPRETATION OF OEDOMETER TEST RESULTS}

The oedometer test produces settlements of a soil specimen for a given applied pressure. The settlements can be converted into strains and plotted as a stress-strain curve. The axes however have been swapped to produce a strainstress curve to preserve the form of the settlement-stress curve. The strain-stress curves for soils 1 and 2 in very loose and very dense conditions are shown in Fig. 3 for both the dry and the saturated states. 


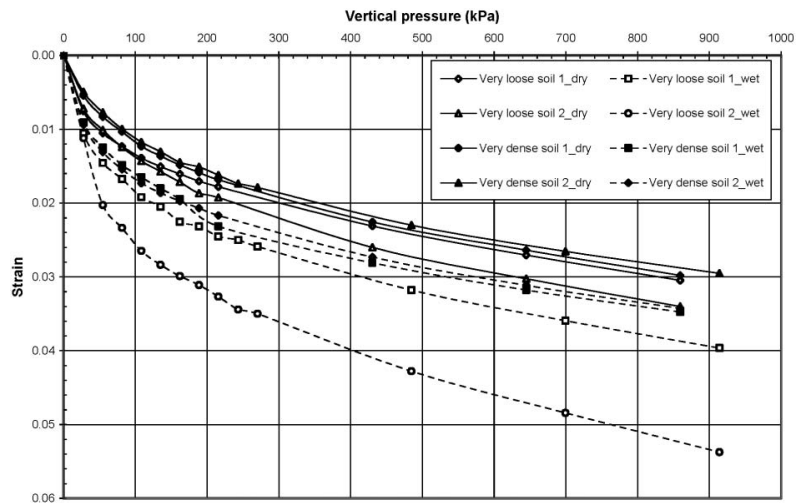

Fig. 3. Strain-stress curves for soils 1 and 2 in very loose and very dense conditions

In Fig. 3, it can be seen that as the vertical pressure increases, the rate of strain increase decreases, indicating that the soil is becoming stiffer. Also, the strains in the saturated test specimens are significantly higher than those in dry specimens, thus giving higher settlements. This is due to the reduction in the unit weight, from bulk unit weight to submerged unit weight, which reduces the effective stresses within the soil by approximately $50 \%$. The reduction in effective stresses and the confining pressures lead to a reduction in the soil stiffness and therefore the settlements are significantly larger for the saturated sands. The tangent to the plots in Fig. 3 give constrained modulus, $E_{\mathrm{d}}$. The Young's modulus $(E)$ can be calculated from the constrained modulus, $E_{\mathrm{d}}$, using a Poisson's ratio of $v=0.15$ in the following equation (Lambe and Whitman, 1979; Mayne and Poulos, 1999):

$$
E=\frac{(1+v)(1-2 v)}{(1-v)} E_{\mathrm{d}}
$$

The Young's moduli thus computed are plotted against the applied vertical pressure in Figs. 4 and 5 for soils 1 and 2 respectively in both very loose and dense conditions under dry and saturated situations. It is quite clear that the Young's modulus to vertical stress relation is approximately bilinear for both the soils, with the break occurring at vertical stress of about $200 \mathrm{kPa}$, for both dry and saturated sands. These values of Young's modulus are particularly high due to the high confining pressure.

When the applied normal stress increases, the confining pressure of the specimen in the oedometer increases as well, and hence the Young's modulus increases. This is clearly evident from the plots in Figs. 4 and 5. The ratio $f_{\text {Esd }}$ is defined as the change in the saturated Young's modulus $\left(E_{\text {sat }}\right)$ to the dry Young's modulus $\left(E_{\text {dry }}\right)$ at the same stress level for both the soils, which is simply the ratio of the slopes of the lines of plots in Figs. 4 and 5. The values of $f_{\text {Esd }}$ are summarised as follows:

For low stress range (approximately $<200 \mathrm{kPa}$ ):

Soil 1 (very loose): $f_{\text {Esd }}=0.758$

Soil 1 (very dense): $f_{\text {Esd }}=0.980$

Soil 2 (very loose): $f_{\text {Esd }}=0.722$

Soil 2 (very dense): $f_{\text {Esd }}=1.119$

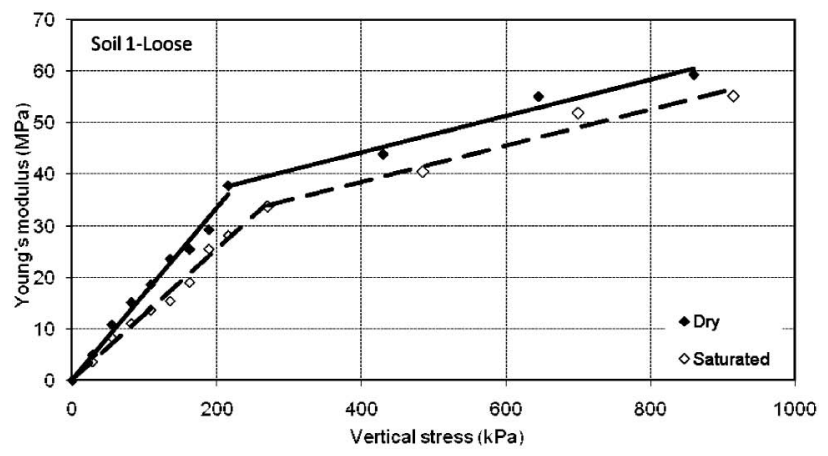

(a)

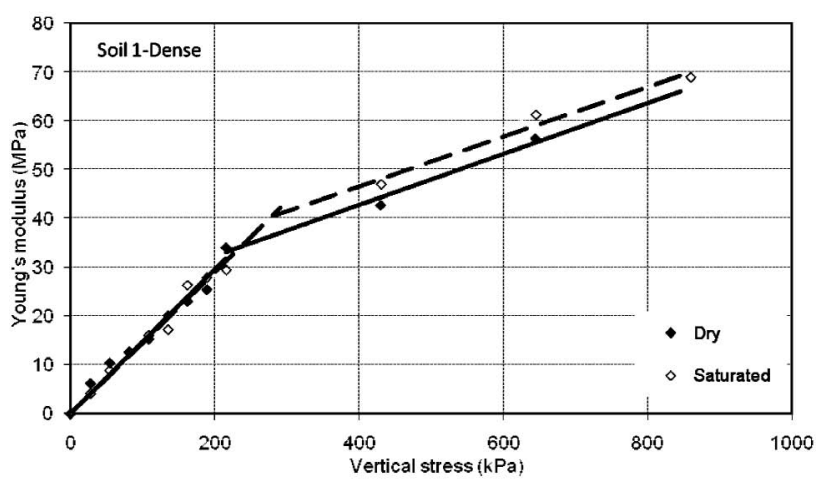

(b)

Fig. 4. Variation of Young's modulus with vertical stress for soil 1: (a) very loose condition and (b) very dense condition

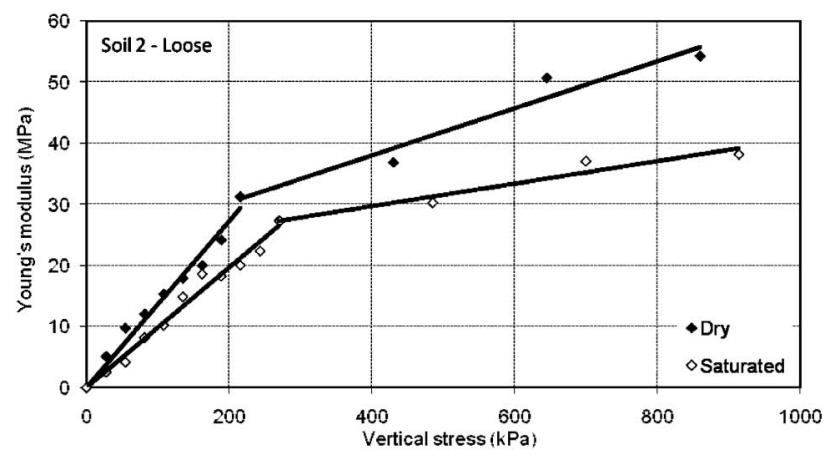

(a)

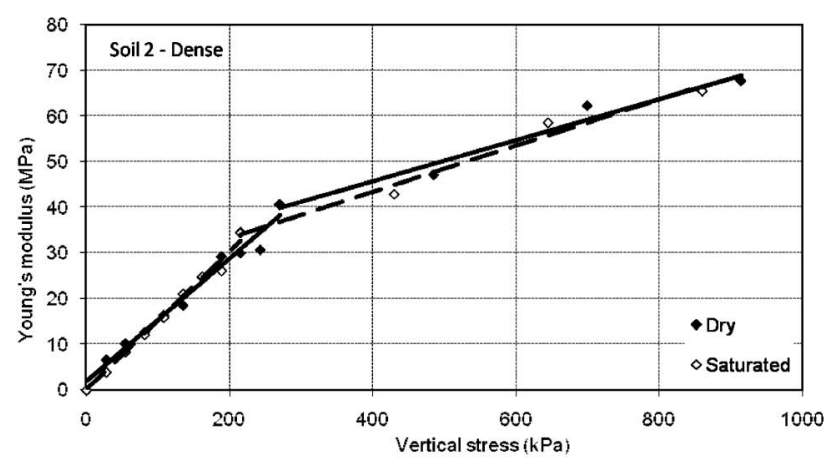

(b)

Fig. 5. Variation of Young's modulus with vertical stress for soil 2: (a) very loose condition and (b) very dense condition 
For high stress range (approximately $>200 \mathrm{kPa}$ ):

Soil 1 (very loose): $f_{\text {Esd }}=0.997$

Soil 1 (very dense): $f_{\text {Esd }}=1.027$

Soil 2 (very loose): $f_{\text {Esd }}=0.474$

Soil 2 (very dense): $f_{\text {Esd }}=1.124$

Here, it is assumed that the break in the bilinear plot in Figs. 4 and 5 occurs at $200 \mathrm{kPa}$.

The rise of water table leads to a reduction in the effective vertical $\left(\sigma_{\mathrm{v}}^{\prime}\right)$ and horizontal $\left(\sigma_{\mathrm{h}}^{\prime}\right)$ stresses beneath the footing. The reduction in $\sigma_{\mathrm{v}}^{\prime}$ and $\sigma_{\mathrm{h}}^{\prime}$ leads to lower values of soil stiffness, and hence increase in settlements. Therefore, a stress reduction factor $\left(f_{\sigma}\right)$ is proposed as:

$$
f_{\sigma}=\frac{\left(\gamma_{\mathrm{d}}-\gamma_{\mathrm{w}}\right)}{\gamma_{\mathrm{d}}} \approx \frac{1}{2}
$$

where $\gamma_{\mathrm{d}}$ is the dry unit weight of the soil being considered, and $\gamma_{w}$ is the unit weight of water.

If the relationship between the Young's modulus and the effective horizontal confining stress is assumed to be linear, then the saturated and dry Young's moduli, $E_{\text {sat }}$ and $E_{\text {dry }}$ respectively for use in settlement analysis will be in proportion to the factors $f_{\sigma}$ and $f_{\text {Esd }}$. Hence, a simple relationship between $E_{\text {sat }}$ and $E_{\text {dry }}$ can be established as:

$$
E_{\mathrm{sat}}=f_{\sigma} f_{\mathrm{Esd}} E_{\mathrm{dry}}
$$

\section{INTERPRETATION OF SETTLEMENT TEST RESULTS}

Figure 6 shows the percent additional settlement, defined as the ratio of the increase in settlement caused by water table rise to the initial elastic settlement multiplied by 100 , of the footing resting on the granular soils in very loose and very dense conditions for each rise of the water table. It can be seen that there is a significant difference in the magnitude of the percent additional settlements observed between the very loose and very dense conditions for both soils, and the percentage of additional settlement is greater in a loose granular soil than in a dense one. In both the granular soils, the rate of increase in the additional settlements increases with the rise of water ta-

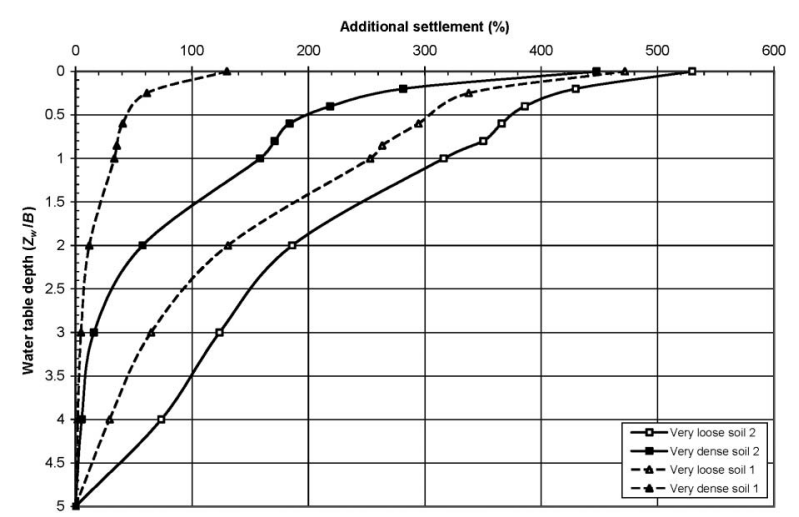

Fig. 6. Additional settlements caused by water table rise in soils 1 and 2 in very loose and dense conditions ble. It is also noted that for soil 2, the percent additional settlements for the very dense condition are significantly higher than for soil 1 . From observations made during the settlement test for soil 2 in very dense condition, it is believed that the footing may have behaved in local or punching shear upon saturation.

\section{THEORETICAL PREDICTIONS AND COMPARISION WITH EXPERIMENTAL RESULTS}

To calculate the additional settlement for each water level rise, a method similar to the Schmertmann (1970) method was used. The strain influence diagram used in the calculations however is not the $0.6-2 B$ distribution suggested by Schmertmann (1970) but rather an approximation of the strain influence derived from elastic theory for a Poisson's ratio of 0.15 . The approximation of the strain influence diagram is shown in Fig. 7. The points for the linear approximation are obtained from Mayne and Poulos (1999), and are for a circular footing of radius $d$, thus when used for the square footing a conversion must be made. An equivalent diameter $B^{\prime}$ for a square footing is given by:

$$
B^{\prime}=\left(\frac{4 B^{2}}{\pi}\right)^{0.5}
$$

The settlement $(\delta)$ of the model footing was calculated using the following equation:

$$
\delta=q_{\text {net }} \sum \frac{\Delta I_{\mathrm{z}} \Delta z}{E_{\mathrm{z}}}
$$

where $E_{\mathrm{z}}$ is the Young's modulus at depth $z$. Since the actual stress under and around the footing is difficult to calculate as described by Boussinesq (1883) and Westergaard (1938), it is therefore difficult to calculate the confining stress and obtain the Young's modulus through the soil profile. To simplify calculations, a constant dry

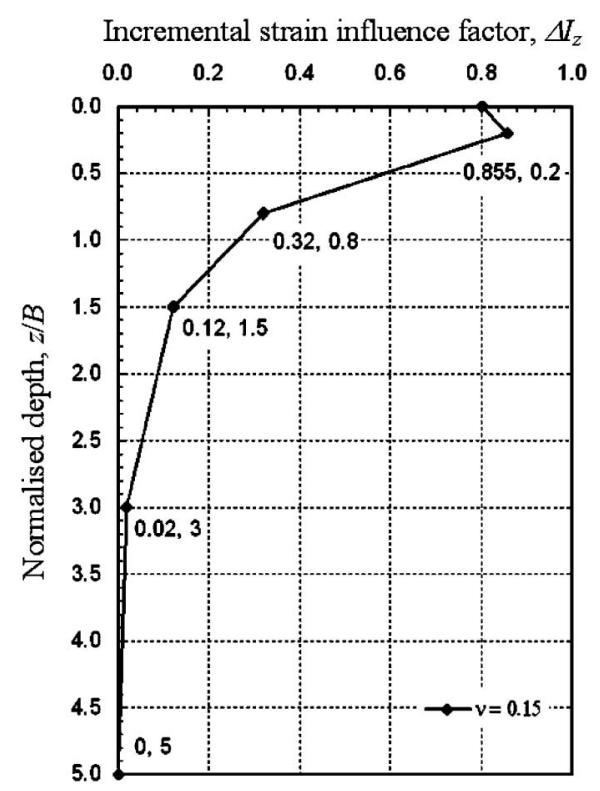

Fig. 7. Approximate strain influence diagram for $v=0.15$ 
Table 1. Additional settlement calculator layout

\begin{tabular}{|c|c|c|c|}
\hline \multicolumn{3}{|c|}{ Footing width, $B(\mathrm{~mm})$} & 100 \\
\hline \multicolumn{3}{|c|}{ Footing pressure, $q_{\text {net }}(\mathrm{kPa})$} & 78.48 \\
\hline \multicolumn{3}{|c|}{ Dry unit weight, $\gamma_{\mathrm{d}}\left(\mathrm{kN} / \mathrm{m}^{3}\right)$} & 16.04 \\
\hline \multicolumn{3}{|c|}{ Dry Young's modulus, $E_{\text {dry }}(\mathrm{MPa})$} & 5.2 \\
\hline \multicolumn{3}{|c|}{$f_{\text {Esd }}$} & 0.98 \\
\hline \multicolumn{3}{|c|}{ Normalised water table depth, $z_{\mathrm{w}} / B$} & 0.4 \\
\hline $\begin{array}{l}\text { Normalised } \\
\text { depth } z / B\end{array}$ & $\begin{array}{l}\text { Normalised } \\
\text { depth block }\end{array}$ & $\Delta I_{\mathrm{z}} \Delta z$ & $\begin{array}{c}\text { Incremental } \\
\text { settlement }\end{array}$ \\
\hline \multicolumn{4}{|l|}{0} \\
\hline 0.2 & $0-0.2$ & 0.0187 & 0.2818 \\
\hline 0.4 & $0.2-0.4$ & 0.0173 & 0.2608 \\
\hline 0.6 & $0.4-0.6$ & 0.0133 & 0.5422 \\
\hline 0.8 & $0.6-0.8$ & 0.0092 & 0.3776 \\
\hline 1 & $0.8-1$ & 0.0066 & 0.2690 \\
\hline 2 & $1-2$ & 0.0166 & 0.6801 \\
\hline 3 & $2-3$ & 0.0060 & 0.2461 \\
\hline 4 & $3-4$ & 0.0017 & 0.0692 \\
\hline 5 & $4-5$ & 0.0006 & 0.0231 \\
\hline
\end{tabular}

Young's modulus was used which was obtained from using the vertical stress at a depth of $0.5 B$ below the footing and reading from Fig. 3. The Young's moduli for soil 1 in very loose and very dense conditions are $0.9 \mathrm{MPa}$ and 5.2 $\mathrm{MPa}$ respectively, and for soil 2 , are $0.7 \mathrm{MPa}$ and 4.7 $\mathrm{MPa}$ respectively. The saturated Young's modulus was calculated from Eq. (3). The additional settlements were calculated in a spreadsheet calculator shown in Table 1. The predicted settlements for each water table rise were calculated and converted to percentage additional settlements and plotted with the actual percentage additional settlements obtained from the settlement tests. In general, the theoretical predictions of the additional settlements are smaller than the experimental observations as seen in Fig. 8 for soils 1 and 2 in very loose and very dense conditions. There are a number of possible factors contributing to deviations of the theoretical predictions from the experimental observations. These factors include the accuracy of the oedometer test results, the assumption of a constant Young's modulus throughout the depth of the soil and the prediction of the Young's modulus based on the assumption of considering the soil to be an elastic continuum. Since, the results of the study on granular soils are based on only a small number of experimental data sets, the findings of the study need further confirmation by experimental testing considering several other types of granular soils.

Most of the settlement prediction methods available in the literature are either elastic or empirical. Elastic analysis is still quite popular for computing settlements of shallow foundations. Schmertmann's (1970) method is widely used world-wide, and the more recent Mayne and Poulos (1999) method has drawn significant attention. The method proposed herein is based on these two methods and assumes that the sands behave elastically, although consideration of non-linearity of the soil behaviour may bring the results closer to the physical observation.

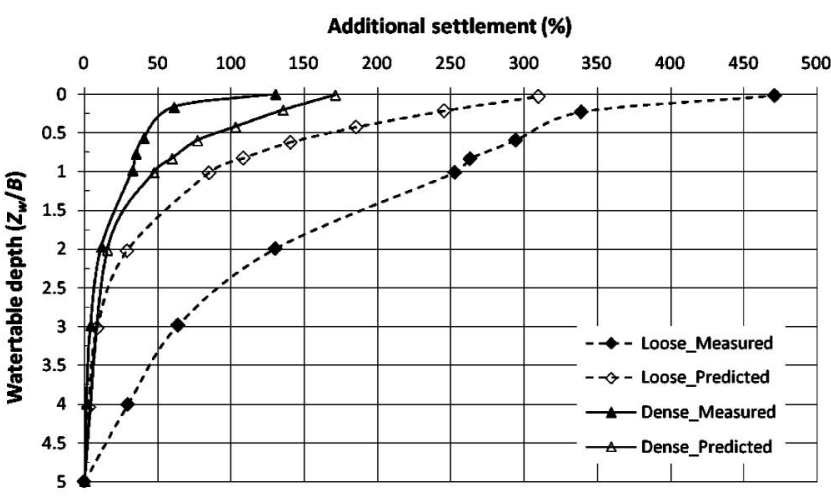

(a)

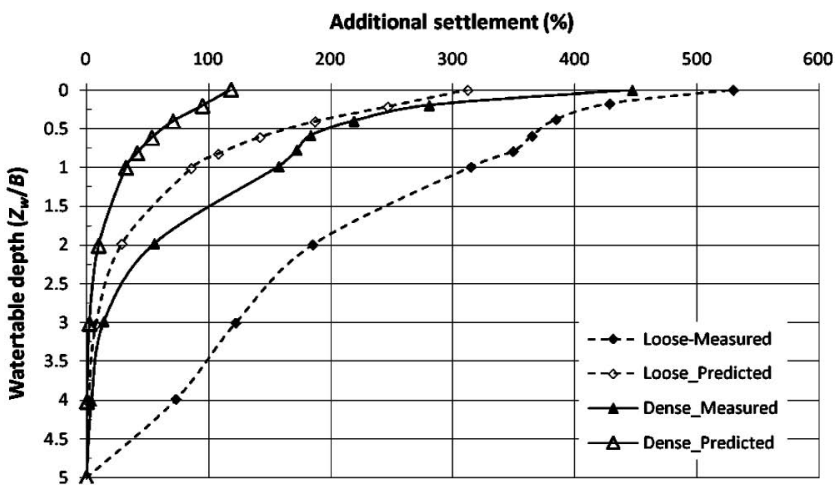

(b)

Fig. 8. Comparison of predicted and actual percent additional settlements in very loose and dense conditions for: (a) soil 1 and (b) soil 2

\section{CONCLUDING REMARKS}

When footings resting on granular soils are subjected to a water table rise, there are additional settlements observed. The cause of the additional settlements is believed to be due to a reduction in the Young's modulus of the soil caused by saturation. In this paper, the oedometer test results for two granular soils in very loose and very dense conditions were reported to observe the change in their Young's moduli on saturation. The actual change observed in the oedometer test was not enough to explain the magnitude of the additional settlements. The Young's modulus however was observed to be dependant on the effective confining stress in the soil. A relation between the saturated and dry Young's modulus of a granular soil was therefore proposed. This relation incorporates a change between the dry and the saturated states observed through oedometer testing and the change in effective confining stress which occurs due to buoyancy forces. Since the effective confining stress is reduced considerably when the water table rises, it contributes to the reduction of the Young's modulus. Utilizing the findings from the oedometer testing, the additional settlements of model footing were predicted and compared to the actual settlements of the model footing through settlement tests conducted in the laboratory. Since, the results of the study 
on granular soils are based on only a small number of experimental data sets, the findings of the study need further confirmation by experimental testing, especially at a large scale, considering several other shapes of the footing, and different types of granular soils. The large scale tests should also be conducted on embedded footings, which generally represent the real life situations.

\section{REFERENCES}

1) AS 1289.0-2000: Method of testing soils for engineering purposes, Part 0: General Requirements of List of Methods, Standards Australia International, Australia.

2) Boussinesq, J. (1883): Application des Potentials à L'Etude de L'Equilibre et du Mouvement des Solides Elastiques, Gauthier-Villars, Paris.

3) Lambe, T. W. and Whitman, R. V. (1979): Soil Mechanics, SI ver- sion, John Wiley and Sons, New York.

4) Mayne, P. W. and Poulos, H. G. (1999): Approximate displacement influence factors for elastic shallow foundations, Journal of Geotechnical and Geoenvironmental Engineering, 125(6), 453-460.

5) Murtaza, G., Athar, M. and Khan, S. M. (1995): Influence of submergence on settlement of footing on sand, Journal of the Institution of Engineers, India, 76(5), 51-54.

6) Schmertmann, J. H. (1970): Static cone to compute static settlement over sand, Journal of the Soil Mechanics and Foundations Division, 96(SM3), 1011-1043.

7) Terzaghi, K. (1943): Theoretical Soil Mechanics, John Wiley and Sons, New York.

8) U.S. Army Corps of Engineers (1990): Engineering and Design-Settlement Analysis, http://www.usace.army.mil/publications/engmanuals/em.htm, Washington, DC, USA.

9) Westergaard, H. M. (1938): A problem of elasticity suggested by a problem in soil mechanics: Soft material reinforced by numerous strong horizontal sheets, Contributions to mechanics of soils, Dedicated to Stephen Timoshenko volume, MacMillan, New York. 